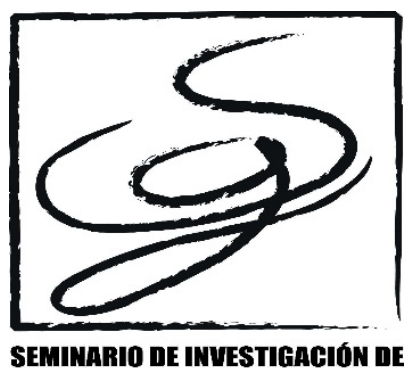

\title{
Bruja gestante: \\ Criminalización patriarcal del cuerpo (no)materno en el acceso al aborto en Argentina
}

Pregnant witch: Patriarchal criminalization of the (non) maternal body in access to abortion in Argentina

\author{
Noelia Rozanski \\ Universidad de Buenos Aires \\ noe.rozanski@gmail.com
}

Fecha de recepción: 02/06/2021 Fecha de evaluación: 01/09/2021

Fecha de aceptación: 07/09/2021

\begin{abstract}
Resumen
El discurso criminológico de la Inquisición condensado en el Malleus Maleficarum en el siglo XV y heredero de prácticas de persecución y tortura desarrolladas a partir del siglo XII, se valió de la imagen de la bruja para ser funcional a sectores de poder en su empresa de aniquilar y diezmar poblaciones enteras e imprimir en los cuerpos modos de ser y actuar necesarios para el desarrollo de un sistema económico que requería un modelo articulado y controlado de producción/reproducción: el capitalismo. Es objetivo de este trabajo analizar la criminalización patriarcal del cuerpo (no)materno en el acceso al aborto en Argentina y las continuidades del discurso demonológico del siglo XV a partir del caso Belén, una mujer que entre 2014 y 2017 estuvo 29 meses detenida por un aborto espontáneo acusada de matar a su "hijo". Para el abordaje del caso, nos valdremos de los aportes teóricos de distintas autoras feministas, y a partir de allí indagaremos cómo el poder punitivo del Estado atraviesa el cuerpo con tecnologías de biopoder, le imprime modos de ser, pensar y actuar, imperativos y prohibiciones, y demoniza con su impronta patriarcal la parte "maldita", subversiva e infame de lo que en este trabajo hemos llamado "bruja gestante".
\end{abstract}

Palabras clave: cuerpo, aborto, criminalización, patriarcado, bruja, Argentina 


\begin{abstract}
The criminological discourse of the Inquisition condensed in the Malleus Maleficarum in the 15th century and heir to the practices of persecution and torture developed from the 12th century, made use of the image of the witch to be functional to sectors of power in its endeavor to annihilate and decimating entire populations and imprinting in the bodies ways of being and acting necessary for the development of an economic system that required an articulated and controlled model of production / reproduction: capitalism. The objective of this work is to analyze the patriarchal criminalization of the (non) maternal body in access to abortion in Argentina and the continuities of the demonological discourse of the 15th century from the case of Belén, a woman who between 2014 and 2017 was detained for 29 months by a spontaneous abortion. To approach the case, we will use the theoretical contributions of different feminist authors, and from there we will investigate how the punitive power of the State crosses the body with biopower technologies, prints ways of being, thinking and acting, imperatives and prohibitions, and demonizes with its patriarchal stamp the "cursed", subversive and infamous part of what in this work we have called "pregnant witch".
\end{abstract}

Key words: body, abortion, criminalization, patriarchy, witch, Argentina

\title{
1. Introducción
}

...me contaron que hay mujeres que tienen miedo al ir a un hospital, con una hemorragia (yo les digo que si van a un sanatorio no les va a pasar nada, ahora si van a un hospital público pueden terminar en la cárcel) yo les digo que no tengan miedo. Que hay que luchar para que no vuelva a pasar nunca más.

Belén

El discurso criminológico de la Inquisición condensado en el Malleus Maleficarum en el siglo XV y heredero de prácticas de persecución y tortura desarrolladas a partir del siglo XII, se valió de la imagen de la bruja para ser funcional a sectores de poder en su empresa de aniquilar y diezmar poblaciones enteras e imprimir en los cuerpos modos de ser y actuar necesarios para el desarrollo de un sistema económico que requería un modelo articulado y controlado de producción/reproducción: el capitalismo.

El Malleus Maleficarum , escrito en 1487 por Jacob Sprenger y Heinrich Krämer, dos monjes de la Orden de Santo Domingo de Guzmán, constituye la primera elaboración orgánica de la criminología moderna, ya que si bien el imperio romano había utilizado la tortura como método de ejercicio del poder punitivo, nunca desarrolló una teoría respecto de la etiología del delito, ni teorizó acerca de formas de control ni prevención criminal. Esta criminología originaria demonológica,

inventó, frente a un Dios ejecutado por el poder punitivo, un enemigo, Satán [del hebreo "enemigo"] y también un 
ejército de seres malignos a sus órdenes, que con la complicidad de los humanos más débiles o inferiores se dedicaba a producir todos los males imaginables, por lo que no quedaba más remedio que oponerle otro ejército (Zaffaroni, 2011: 27)

La caza de brujas se justificó en la persecución de las mujeres por ser seres inferiores, débiles, influenciables por Satán y consecuentemente una amenaza para la sociedad. Comienza entonces un proceso de maternización de los cuerpos femeninos circunscriptos al espacio del hogar en el trabajo de reproducción de mano de obra, que entrado el siglo XIX se verá justificado por el discurso médico, y será nuevamente funcional al control de las poblaciones. Esta búsqueda de explicaciones científicas al origen del crimen cristalizará en la criminología positivista con la imagen de la "mala mujer", "mala madre", asociando desde planteos moralizantes, la falta al cumplimiento del estereotipo con la "mala vida".

Es objetivo de este trabajo analizar la criminalización patriarcal del cuerpo (no)materno en el acceso al aborto en Argentina y las continuidades del discurso demonológico del siglo XV a partir del caso Belén, una mujer que entre 2014 y 2017 estuvo 29 meses detenida por un aborto espontáneo. Al momento de la detención tenía 25 años, desconocía estar embarazada, y había acudido al Hospital Avellaneda de la ciudad de Tucumán por un dolor abdominal persistente hacía una semana. Sin darle explicaciones, y luego de practicarle intervenciones varias que van desde un legrado y vigilancia policial hasta exhibirle un feto muerto -su "hijo" al que supuestamente "asesinó"-, en cuestión de horas, con un relato de los hechos contradictorio en horarios, con un feto que fue encontrado muerto por traumatismo de cráneo en el inodoro de un baño del Hospital, sin ADN que acreditara filiación y con incongruencias respecto a la edad gestacional -22 semanas, 27, luego 32- Belén queda detenida por homicidio agravado por el vínculo.

Para el abordaje del caso, nos valdremos de los aportes teóricos de distintas autoras feministas ${ }^{1}$, y a partir de allí indagaremos cómo el poder punitivo del Estado atraviesa el cuerpo con tecnologías de biopoder, le imprime modos de ser, pensar y actuar, imperativos y prohibiciones, y demoniza con su impronta patriarcal la parte "maldita", subversiva e infame de lo que en este trabajo hemos llamado "bruja gestante".

\section{Biopolítica de la reproducción}

me hicieron entrar a la sala de parto, me hicieron dormir, yo no sabía que estaba embarazada, yo creía que era una hemorragia por tantos medicamentos que había tomado. A mi preguntaban si estaba embarazada y yo contestaba que no. Nunca me dijeron que había un bebé. Me hicieron el legrado, después de ahí estuve hasta las 06:20 en la sala de parto y ahí vino un

\footnotetext{
${ }^{1}$ Federici y Fraser desde un feminismo de orden anticapitalista; Preciado, Butler, Wittig, Barrancos y Segato para indagar en la relación de género, cuerpo y feminismo.
} 
enfermero y me hizo ver. Yo nunca quise empujar. Me hizo ver en una cajita el feto (...) Nada que ver el relato que dijeron. Cómo piensan que yo voy a hacer esa crueldad, yo no soy así. Cómo pueden inventar que yo voy a tratar de empujarlo por el inodoro" (Cámara penal. Sala III. Tucumán, Belén s/homicidio doblemente agravado por el vínculo y alevosía 19/04/2016).

El derrotero de violencia institucional que vivió Belén desde su entrada al Hospital Avellaneda la madrugada del 21 de marzo de 2014 refleja el legado que el patriarcado nos imprimió en el cuerpo desde los tiempos de la Inquisición. La denuncia del personal médico, la imputación de un homicidio sin pruebas de ADN, el mote de "asesina" hasta su entrada a prisión muestran un conjunto de tecnologías de poder disciplinario atravesando su piel.

Esta biopolítica de control del cuerpo femenino tuvo su génesis en el período de acumulación primitiva que posibilitó el surgimiento del modelo capitalista, y operó como elemento central de lo que posteriormente se constituyó en feminidad hegemónica. Un nuevo orden que "como una prisión” (Federici, 2015) limitó a las mujeres a la función reproductiva.

En este sentido es preciso entender el control del cuerpo en el contexto del modo binario capitalista, donde los hombres comenzaron a ser el sujeto único universal en detentar el poder de la producción, y las mujeres acabaron confinadas al espacio del hogar para el cuidado y desarrollo de fuerza de trabajo, un espacio que se inscribió en el ámbito de lo privado pero con fuertes implicancias en lo público como condición necesaria para el funcionamiento de la producción capitalista, una "política del cuerpo" que operó en una falsa idea de los límites de privacidad de la familia.

El periodo de acumulación primitiva marca tres fenómenos relevantes para la acumulación capitalista: una nueva división sexual que ligó lo femenino a la función reproductiva de la fuerza de trabajo; un nuevo orden patriarcal, donde esa función reproductiva desarrollada en la esfera del hogar, excluyó a las mujeres del trabajo asalariado y las subordinó a los hombres en el aspecto económico; y por último, la mecanización del cuerpo, erigiendo a las mujeres en "máquina de producción de nuevos trabajadores". Según Silvia Federici,
en la sociedad capitalista, el cuerpo es para las mujeres lo que la fábrica es para los trabajadores asalariados varones: el principal terreno de su explotación y resistencia, en la misma medida en que el cuerpo femenino ha sido apropiado por el Estado y los hombres, forzado a funcionar como un medio para la reproducción y la acumulación de trabajo. En este sentido, es bien merecida la importancia que ha adquirido el cuerpo, en todos sus aspectos - maternidad, parto, sexualidad-, tanto dentro de la teoría feminista como en la historia de las mujeres (Federici, 2015: 28)

Como terreno de explotación, el cuerpo fabrica lo femenino a la vez que es objeto de imposiciones que determinan esa construcción identitaria: 
desde esa perspectiva, una mujer es principalmente un cuerpo-máquina con útero, cuya autonomía se diluye a la orden de imperativos de maternidad que confluyen como engranaje de un modelo económico que le requiere reproducción de mano de obra en masa. El ser se reduce a "cuerpo gestante", "órgano-trabajo cuya producción de riqueza biopolítica ha sido totalmente expropiada y ocultada bajo la cobertura de una función puramente biológica" (Preciado, 2019: 73), espacio biopolítico de excepción, vigilancia y tutela política, depositario de disputas entre distintos poderes, de mecanismos y tecnologías de control donde se aloja y construye lo público y se fabrica la soberanía nacional.

En este contexto, en el que "hombre" y "mujer" se presentan como dos expresiones sociales y políticas dentro de un sistema heterosexual que los sitúa en los dos grandes polos del sistema capitalista -producción y reproducción-, la heterosexualidad asociada al gran imperativo de la maternidad se presenta como régimen político garante de la relación entre la identidad de género y ciertos órganos concebidos como sexuales y reproductivos (Wittig, 2001).

Sin embargo, el cuerpo y ese género que arbitrariamente le ha impuesto ciertas obligaciones en detrimento de su libertad, también puede entenderse como resistencia. Si bien es posible considerar que el género "califica" y que universaliza el marco binario del sexo en la constitución de una episteme conceptual (Wittig, 1984), también es cierto que puede ser performativo dado su carácter abierto, incompleto, siempre en construcción en relación a la coyuntura, al momento y el deseo, sujeto a contradicciones e identidades que bien pueden alternadamente instaurarse $\mathrm{o}$ abandonarse (Butler, 1990;2018), correrse de estereotipos, cuestionarlos, promover nuevas formas identitarias o transformar los sentidos de las formas que social y políticamente conocemos y se nos presentan como entidades inmutables y acabadas.

Joan Scott (1996) señala cuatro dimensiones en las que el género puede expresarse en tanto forma de relaciones significantes de poder: las representaciones simbólicas, los conceptos normativos, las instituciones sociales y las identificaciones subjetivas. De modo que dentro del conjunto de prácticas que culturalmente se asocian a "hombre" o "mujer" queda suficiente margen de acción para que las identidades trasciendan los límites que tradicionalmente les son impuestos, subvirtiendo así la construcción binaria de lo masculino y lo femenino.

¿Podemos pensar maternidades-otras? En este sentido, cabría considerar la noción de cuerpo gestante en las antípodas de la relación causal entre mujer y reproducción, ya sea porque puede un sujeto gestante mujer decidir interrumpir un embarazo, no concebir o maternar de un modo no hegemónico; ya sea porque un sujeto gestante hombre decida hacer uso de su útero. Así se desdibuja el sentido patriarcal del cuerpo femenino porque no se reduce género ni útero a las mujeres sino a una cuestión cultural más amplia, ni tampoco se confina a la mujer al trabajo no pago de la reproducción.

Si utilizamos la categoría de género en sentido de resistencia, advertimos a lo masculino y lo femenino como posiciones relativas de la 
vida social, que si bien son representadas por anatomías específicas, pertenecen a una trama de relaciones que condiciona, pero no necesariamente determina. Como advierte Rita Segato, "[los géneros pueden ser] posiciones y lugares en una estructura de relaciones abierta y disponible para ser ocupada por otros significantes." (Segato, 2010: 56)

Cuando una mujer aborta "el cuerpo femenino es un cuerpo sustraído a la exclusiva ratio médica sobre todo si se cruza con el vertedero patriarcal de sancionar la moral femenina" (Barrancos, 2019: 25). Cuando una mujer aborta se desprende de su útero un significante polisémico que implica tanto disquisiciones sobre criminalidad como las más variadas reflexiones de qué es "ser" mujer. Cuando una mujer que aborta es condenada por la justicia como "homicida", a su cuerpo encarcela el sistema judicial pero también médico. Belén fue criminalizada desde que ingresó al hospital en total violación del secreto profesional que el personal médico debió guardar, y que fue el detonante de los siguientes 29 meses que pasó en prisión por lo que en su ingreso al centro de salud la madrugada del 21 de marzo de 2014 fue diagnosticado como abdomen agudo y con el correr de las horas derivó en "aborto espontáneo incompleto sin complicaciones" (fs. 65). Tal como consta en la causa:

La situación de vulnerabilidad de la mujer cobra especial relevancia al haber llegado al nosocomio apremiada por su situación de salud, impelida a colocar en forma involuntaria su propio cuerpo en manos de profesionales del estado que se suponía que debían guardar silencio de todo lo que hubieran conocido por motivo de su actividad médico asistencial. Es decir que en modo alguno puede considerarse que su sometimiento al servicio médico fuera voluntario, ya que se encontraba entre la espada o la pared, ante el inhumano dilema: la muerte o la cárcel (CSJ Tucumán, Sala Civil y Penal, SSS s/ Homicidio agravado por el vínculo mediando circunstancias extraordinarias de atenuación (Caso Belén), reg. $n^{\circ}$ 329/17, rta. 23/03/2017)

¿Por qué una emergencia obstétrica causada por el cuerpo en un instante totalmente involuntario termina en una condena por homicidio? ¿Por qué el pedido de ayuda médica deriva en una denuncia? ¿Por qué el acceso a la salud se vuelve imposible si no se entra en el circuito privado de atención? ¿Por qué la suerte de las mujeres pobres se debate entre la muerte o la cárcel sin otra opción posible?

La criminalidad del aborto recae en la fuerza cuestionadora del control de la libertad del cuerpo impuesto desde la inquisición. Cuando una mujer aborta, intencionalmente o no, aún si abortara espontáneamente más allá de su voluntad, cambia cuerpo como explotación por "soberanía del cuerpo", hace uso de una "voluntad sobre el cuerpo" (Barrancos, 2019) que le compete solo a sí misma, pone en jaque al patriarcado, desarticula su sentido. 


\section{Violencia institucional en el acceso al aborto legal}

La actividad acusatoria del fiscal se encaró desde un primer momento con el prejuicio de culpabilidad de la mujer (...) Y la violencia institucional acaecida en el ámbito médico y judicial se enanca inmediatamente con la cuestión de género, porque probablemente muchas de las graves falencias apuntadas no se hubieran verificado en un caso con un hombre como presunto autor. Para saber si los estereotipos de género estuvieron presentes en este proceso, sólo hace falta preguntarse: ¿se hubiese llegado a una condena de homicidio agravado por el vínculo de un hombre en una causa donde el cuerpo del delito se perdió y no hay datos que permitan conocer la efectiva relación entre víctima y victimario? ¿con una autopsia con incongruencias tales como el sexo de la víctima o su edad gestacional y con una causa de la muerte no determinada de forma clara y precisa? ¿se hubiese avalado que la defensa no realizara planteo alguno frente a estas situaciones y ni propusiera prueba de descargo? ¿Se hubiera permitido que la defensa ocurriera en sentido contrario a la posición de inocencia sostenida en las declaraciones y palabras del acusado en todo momento? (CSJ Tucumán, Sala Civil y Penal, SSS s/ Homicidio agravado por el vínculo mediando circunstancias extraordinarias de atenuación (Caso Belén), reg. $n^{\circ} 329 / 17$, rta. 23/03/2017)

El juicio moral que vivió Belén da cuenta de un conjunto de prácticas que conforman un camino laberíntico en el que las personas gestantes quedan atrapadas ante situaciones de interrupción del embarazo. Esta praxis jurídica acompaña y recrudece los mecanismos de vulneración de derechos llevados a cabo por el sistema de salud, a la vez que reproduce lógicas de opresión que derivan de estereotipos de género ${ }^{2}$ que sitúan a las mujeres en la función materna en detrimento de derechos como la salud, la vida, la igualdad y la no discriminación. El impedimento al acceso al aborto seguro representa una de las formas de violencia contra las mujeres en que se manifiesta el sentido androcéntrico del sistema de justicia, replicadas en otras instituciones del Estado como las agencias de salud, educación o de gobierno en cualquiera de sus formas.

\footnotetext{
${ }^{2}$ Respecto de los "estereotipos de género", la Corte Interamericana de Derechos Humanos ha dicho en "González y otras (Campo Algodonero) c/México" (16/11/2009), párrafo 401: "el estereotipo de género se refiere a la preconcepción de atributos o características poseídas o papeles que son o deberían ser ejecutados por hombres y mujeres respectivamente (...) Es posible asociar la subordinación de la mujer a prácticas basadas en estereotipos de género socialmente dominantes y socialmente persistentes, condiciones que se agravan cuando los estereotipos se reflejan, implícita o explícitamente, en políticas y prácticas, particularmente en el razonamiento y el lenguaje de las autoridades (...) La creación y uso de estereotipos se convierte en una de las causas y consecuencias de la violencia de género contra la mujer."
} 
A través de la criminalización, o de la omisión en brindar asistencia, información, o el desarrollo de políticas públicas para la ampliación de derechos, el Estado incumple un deber que le es exigido tanto en el derecho interno como internacional, ejerciendo violencia institucional. En los términos del art. 6.b de la Ley 26.485 de protección integral para prevenir, sancionar y erradicar la violencia contra las mujeres en los ámbitos en que desarrollen sus relaciones interpersonales, se entiende como violencia institucional contra las mujeres:

aquella realizada por las/los funcionarias/os, profesionales, personal y agentes pertenecientes a cualquier órgano, ente o institución pública, que tenga como fin retardar, obstaculizar o impedir que las mujeres tengan acceso a las políticas públicas y ejerzan los derechos previstos en la ley.

Es así que cuando hablamos de violencia contra las mujeres estamos dando cuenta de la discriminación estructural del sistema de justicia, solapada tras la ficción de la igualdad formal de derechos que esencialmente han sido pensados desde concepciones androcéntricas. Como plantea Encarna Bodelón,

la idea de que la protección de los derechos de las mujeres en los códigos penales está garantizada por la igualdad formal, olvida que dichos códigos se configuraron de espaldas, olvidando y negando, a las violencias más frecuentes que sufren las mujeres, las violencias machistas (Bodelón, 2014: 137)

Los Estados tienen la obligación legal, y el deber de garantía para el pleno ejercicio de los derechos consagrados en los instrumentos de derechos humanos que suscriben en el marco del Sistema Interamericano de Derechos Humanos, y asimismo les corresponde adoptar medidas afines en el derecho interno. En este sentido, el Comité CEDAW (Convención sobre la eliminación de todas las formas de discriminación contra la mujer) en su Recomendación General Número 24 "La mujer y la salud" (1999), establece que

en relación con los servicios de aborto, los Estados deben avanzar en la eliminación de cualquier provisión legal que penalice a las mujeres que se han sometido a la práctica de un aborto.

De igual modo, en su Declaración sobre la Violencia contra las Mujeres, Niñas y Adolescentes y sus Derechos Sexuales y Reproductivos (2014), el Mecanismo de Seguimiento de la Convención de Belém Do Pará (MESECVI) señaló que es un deber de los Estados eliminar el aborto inseguro que se cobra la vida de las mujeres.

En la Observación General $N^{\circ} 14$, sobre Derecho al disfrute del más alto nivel posible de salud (2000) el Comité de Derechos Económicos, Sociales y Culturales, planteó que

el ejercicio del derecho de la mujer a la salud requiere que se supriman todas las barreras que se oponen al 
acceso de la mujer a los servicios de salud, educación e información, en particular en la esfera de la salud sexual y reproductiva.

Y en la Observación General № 22 sobre el Derecho a la salud sexual y reproductiva (2016), planteó que:

La prevención de los embarazos no deseados y los abortos en condiciones de riesgo requiere que los Estados adopten medidas legales y de políticas para garantizar a todas las personas el acceso a anticonceptivos asequibles, seguros y eficaces y una educación integral sobre la sexualidad; liberalicen las leyes restrictivas del aborto; garanticen el acceso de las mujeres y las niñas a servicios de aborto sin riesgo y asistencia de calidad posterior a casos de aborto; y respeten el derecho de las mujeres a adoptar decisiones autónomas sobre su salud sexual y reproductiva.

En Argentina, se sancionó el 30/12/2020, y entró en vigencia el 24/01/2021, la Ley 27.610 de Acceso a la Interrupción Voluntaria del Embarazo (IVE). Ese hito, que reconoce el aborto a libre demanda hasta la semana catorce de gestación inclusive, y condensa la lucha del movimiento de mujeres por el derecho a decidir sobre el propio cuerpo y los propios planes de vida desde la vuelta de la democracia en 1983, constituye un gran punto de inicio para la ampliación de derechos en materia (no)reproductiva y el reconocimiento de demandas durante décadas negadas. El derrotero por el acceso a la interrupción voluntaria del embarazo es un proceso de larga data que en algunos casos al momento de llevar el ejercicio de derechos a la práctica aún presenta un marcado sesgo de injusticia reproductiva que, a través de la interpretación restrictiva de la norma, se reduce a un modelo de criminalización y penalización total.

El aborto en Argentina es legal desde 1921 de acuerdo al art. 86 del Código Penal argentino (CPA). Esto implicó hasta la sanción de la Ley 27.610 de Acceso a la Interrupción Voluntaria del Embarazo (IVE) un enfoque único para regular el aborto bajo el "modelo de causales" o indicaciones: el aborto no es punible si se ha realizado con el fin de evitar un peligro para la vida o la salud de la mujer [o la persona gestante], y/o si el embarazo proviene de una violación. En 2012, la Corte Suprema de Justicia de la Nación se pronunció en el fallo F.A.L. s/medida autosatisfactiva. F.259. XLVI sobre el modo de interpretación del art. 86 del Código Penal Argentino (CPA), sentando precedente para un sentido interpretativo amplio: la práctica debía resolverse sin dilación y sin recurrir a la vía judicial privilegiando la interpretación legal más favorable a la persona frente al poder estatal, y extendiendo la causal violación a toda mujer que sea víctima de ese delito y no únicamente a aquellas con alguna patología vinculada a la salud mental. En este sentido, el fallo F.A.L. s/medida autosatisfactiva estableció: 
-Invocando los principios de estricta legalidad y pro homine, privilegiar la interpretación legal más favorable a la persona frente al poder estatal:

priorizar una exégesis que esté en consonancia con el principio político criminal que caracteriza al derecho penal como la última ratio del ordenamiento jurídico y a privilegiar la interpretación legal que más derechos acuerde al ser humano frente al poder estatal (Cdo 17).

-Invocando los principios de igualdad y de prohibición de toda discriminación, extender la causal violación a toda mujer que sea víctima de ese delito, y no únicamente a aquellas con alguna patología vinculada a la salud mental:

reducir por vía de interpretación la autorización de la interrupción de los embarazos sólo a los supuestos que sean consecuencia de una violación cometida contra una incapaz mental implicaría establecer una distinción irrazonable de trato respecto a toda otra víctima de análogo delito que se encuentre en igual situación y que, por no responder a ningún criterio válido de diferenciación, no puede ser admitida (Cdo 15).

-Invocando el principio de reserva, eliminar todo requisito de trámite judicial para acceder a un aborto legal en los términos que la ley prevé:

a la luz del principio de reserva constitucional (artículo 19 in fine de la Constitución Nacional), ha de concluirse en que la realización del aborto no punible allí previsto no está supeditada a la cumplimentación de ningún trámite judicial (Cdo 8).

Posterior a la sanción de la Ley 27.610 de Acceso a la Interrupción Voluntaria del Embarazo (IVE) comenzó a regir un sistema mixto: se mantuvo el modelo de causales para abortos a partir de la semana quince de gestación, y se incluyó el modelo de plazos para la interrupción voluntaria del embarazo hasta la semana catorce de gestación inclusive.

En 2014, al momento en que Belén llega al Hospital con una gestación de aproximadamente dieciocho semanas, el derecho a la interrupción voluntaria del embarazo no estaba reconocido. Sin embargo, su caso es representativo del estigma que aún recae en el acceso al aborto. Probablemente, hubiera vivido el mismo camino de violencia institucional, en primer lugar porque desconocía su estado de embarazo, lo cual podría haberse interpretado como lo hizo el personal de salud que la atendió: intención de disimular su accionar criminal, y en segundo lugar, porque al no ser posible interrumpir el embarazo por el modelo de plazos, ya que superaba las catorce semanas de gestación inclusive, se hubieran presentado reticencias a encuadrar la interrupción en alguna de las causales, como ocurrió en 2014.

Si bien el caso no responde a la causal violación, todo el proceso de asistencia médica para la culminación del aborto espontáneo que comenzó 
posterior al ingreso al Hospital, podría encuadrarse en la causal salud ${ }^{3}$ siguiendo un criterio amplio de interpretación, y según el Protocolo para la atención integral de las personas con derecho a la interrupción legal del embarazo del Ministerio de Salud de la Nación ${ }^{4}$ en ese entonces vigente. Sin embargo, Belén fue injustamente criminalizada por una total y absolutamente intencionada interpretación restringida de un derecho que le pertenecía, y es importante dar cuenta de ello para eliminar las barreras de acceso al aborto seguro, evitar la condena moral a una maternidad forzada y erradicar la violencia institucional a la que mujeres como ella son cotidianamente sometidas.

\section{Belén "bruja gestante"}

...después de dar a luz a su hijo, BÉLEN cortó el cordón umbilical que unía la placenta con el cuerpo de su hijo, luego lo anudó y con claras intenciones de provocar la muerte de su hijo, lo arrojó por las cañerías del baño (...) Con su ilícito accionar provocó en su hijo un traumatismo encéfalocraneano, lesión que ocasionó el óbito del niño. Luego de consumado su accionar, se retiró del baño y se dirigió nuevamente al consultorio donde estaba siendo atendida, quedando el cuerpo de su hijo, ya sin vida, atascado en la cañería del inodoro (Cámara penal. Sala III. Tucumán, Belén s/homicidio doblemente agravado por el vínculo y alevosía 19/04/2016)

Belén gestó, pero no "maternó", o lo hizo de un modo disruptivo al que se espera del cuerpo-mujer, no deseó, o lo hizo en un sentido distinto del de la reproducción, no cuidó, o no lo hizo de acuerdo con su "condición femenina", transgredió la reducción de la subjetividad a la maternidad, fue criminalizada y expuesta al castigo penal y moral por "matar" a su "hijo".

Las reiteradas alusiones a su maternidad y la imputación de homicidio sin pruebas de ADN nos remiten al sentido de la criminalidad femenina del siglo XV en Europa. La caza de brujas como mecanismo de control social fue funcional a un modelo económico naciente que fundó su producción en el trabajo no pago de reproducción social realizado por las mujeres en el hogar. La maternidad, antes situada en el espacio privado,

\footnotetext{
${ }^{3}$ Si bien la causal salud contemplada en el art. 86 refiere al riesgo generado por el embarazo, podría entenderse ese riesgo en los términos del aborto espontáneo: el embarazo interrumpido que luego del cual Belén requirió de asistencia y en lugar de ello fue atrapada en un derrotero de criminalización y violencia institucional.

${ }^{4}$ El Protocolo establece: la salud como concepto integral que involucra las dimensiones física, mental y social, de acuerdo a lo establecido por la Organización Mundial de la Salud (OMS); el peligro a la salud como posibilidad y no necesariamente como configuración de daño; la protección del derecho a la igualdad ante la ley y no discriminación en el proceso de atención médica; la obligación del personal médico de actuar conforme los criterios de interpretación establecidos por la CSJN en F.A.L., pudiendo ser responsabilizados penal, civil o administrativamente en caso de no cumplimiento.
} 
pasó a ser una cuestión de Estado, y salir de ese estereotipo ser bruja y por ende criminal.

Asimismo, en la época, a todo fenómeno que no pudiera ser explicado desde la razón se le atribuía origen demonológico. Ciertas conductas como la muerte de bebés al nacer, abortos espontáneos, o cualquier otra situación desconocida era entendida como producto de la acción sobrenatural o de maleficios realizados por enviados de Satán. El origen del delito también se entendía así, aunque allí ya con los marcados intereses económicos del capitalismo naciente, se siguió la filosofía que San Agustín desarrolló en el siglo IV. Su pensamiento, citado en el Malleus Maleficarum, postulaba la existencia de una estructura binaria dicotómica conformada por el Bien y el Mal, una suerte de sistema de dos ciudades contrapuestas -la de Dios y la de Satán- donde el mal era consecuencia de la caída de los ángeles que hicieron uso inadecuado de su libertad y esperaban el juicio final. Ese mal operaba a través de seres humanos débiles, más vulnerables a las influencias del ángel caído maléfico por excelencia: Satán (Zaffaroni, 2011).

La mujer fue considerada desde el relato religioso el ser más débil. El Malleus Maleficarum afirma su inferioridad biológica e intelectual desde una hipótesis que nuevamente sitúa al cuerpo como elemento fundamental: nacida de una costilla curva del hombre, su naturaleza indica la desviación de la rectitud adecuada. Las brujas subvierten la razón con la lógica de lo irracional y con un saber que se presenta como resistencia a la conversión disciplinaria del cuerpo y a la racionalización capitalista que lo destina al trabajo no pago de alojar/generar mano de obra.

Alí radica la criminalización de su control sobre la reproducción, y su masacre bajo la acusación de brujería. Allí se funda la estructura inquisitorial que se replicó a lo largo de la historia: se alega un peligro cuya magnitud genera un estado de emergencia que sólo es posible de resolver librando una guerra contra el mal. En términos de Federici,

las mujeres eran acusadas de ser poco razonables, vanidosas, salvajes, despilfarradoras. La lengua femenina, era especialmente culpable, considerada como un instrumento de insubordinación (Federici, 2015: 181).

En La mujer delincuente, Lombroso y Ferrero (1893;2004) señalaron que las mujeres están menos inclinadas congénitamente al delito que los hombres. En ese trabajo, articulado con otros en los que desarrollaron categorías como "monstruosidad" o "criminal nato", planteaban que, si bien la inferioridad biológica de la mujer la convertía en sujeto con poca habilidad para planificar un delito, eso no la hacía menos criminal que el hombre: las mujeres cometían menos delitos que los hombres, pero eran más perversas y crueles, insensibles al dolor, deficientes morales, celosas y vengativas.

Al igual que la criminología originaria y positivista comparten la impronta misógina en el discurso. Si la inquisición justificaba la inferioridad de la mujer en el relato bíblico -como subproducto del hombre por su nacimiento a partir de una costilla curva- el positivismo criminológico planteaba una explicación desde la ciencia: la corteza cerebral, 
particularmente en los centros psíquicos, es menos activa que la del hombre.

La delincuencia en las mujeres era menor, a excepción de los infanticidios, un tipo de delito que no sólo se asociaba a factores congénitos, innatos, ligados a la herencia o a la inmoralidad, sino que además incluía la anormalidad vinculada a la transgresión del imperativo de maternidad y el amor, atributos considerados "naturalmente" femeninos. Los infanticidios significaban menos del $1 \%$ de delitos contra la vida, aunque la prensa les otorgó gran relevancia. Según Julieta Di Corleto (2018):

En 1890 los infanticidios que llegaban a conocimiento de la policía representaban el $0,43 \%$ de los delitos contra la vida. En 1910, el porcentaje ascendería al $0,54 \%$ y el de los abortos al 0,39\%; de manera que, a la luz de lo que establecían las estadísticas policiales, la participación exclusiva de las mujeres en hechos de estas características seguía siendo mínima (Di Corleto, 2018: 55)

La producción intelectual y las publicaciones en revistas académicas siguieron a misma línea. La "loca moral infanticida" es según José Ingenieros (1916), un tipo de "anormal congénito", cuya conducta es resultado de causas orgánicas que la llevan a no poder adaptar su conducta a la moral del medio en que vive. Huérfana de madre y padre, criada en una Casa de Expósitos, sirvienta y prostituta, Ingenieros repara en su transgresión al mandato materno y al amor, lo que Lombroso denomina "función social [de la mujer]".

En su artículo "La dismaternidad en la mujer delincuente", publicado en 1899 en Buenos Aires, en la revista Criminalogia Moderna, Lombroso definió la dismaternidad como "aquel tedio o aversión hacia los hijos, que yo anotaría como característico de los criminales..." (Lombroso, 1899: 201) circunscribiendo la criminalidad de la mujer a su "función social: al amor y a la maternidad", y vincula el delito a la falta de "caracteres femeniles" que clasifica en corporales: aspecto viril, vellos desarrollados, cabellos obscuros (sic), etc.; y morales: la dismaternidad y la falta de pudor (Lombroso, 1899: 201).

Asimismo, la alusión a la histeria, como a los factores hereditarios $u$ otras causas biológicas vinculadas al delito, se justificaron con la inclusión de la "criminología clínica", un saber de "expertos" destinado a diagnosticar la "peligrosidad", un discurso que fue fundamental para el positivismo criminológico que se pretendía objetivo y que para ello necesitaba fundarse a partir de la voz de la ciencia. Esa voz de autoridad la portaron los peritos, médicos cuya función fue brindar pruebas observables e irrefutables de la criminalidad de una persona. A decir de Zaffaroni:

Con los médicos y su reduccionismo racista se confirmaba que los delincuentes eran degenerados semejantes a los salvajes colonizados y debían ser tratados de modo similar a éstos, en tanto que las personas decentes eran biológicamente superiores $y$, 
por ende, inmunes al poder punitivo (Zaffaroni, 2011:

96).

La referencia al saber clínico como argumento de la criminalidad en las mujeres también es retomada por Ricardo Del Campo. En "Madres criminales. Los infanticidios de La Magdalena" (Del Campo, 1899: 277279), publicado en Buenos Aires, en la revista Criminalogía Moderna en el mismo año que Lombroso publicó su artículo sobre dismaternidad, el autor vincula la "ausencia absoluta del sentido de la maternidad" con las "intolerancias fisiológicas de la moralidad convencional" y la "perversión fisio-psíquica", y las circunscribe a un delito específico: el infanticidio. En su texto analiza el doble infanticidio cometido por Marcelina Arteyas en la localidad de Magdalena, Provincia de Buenos Aires:

sobre la infanticida reciente, tengo a la vista elementos suficientes para llegar a la conclusión de que se trata de una delincuente nata, en cuyo fondo antropológico sensiblemente degenerado, resulta en primer término la más completa atrofia del sentido moral (...) Al factor hereditario oficialmente comprobado [se acusa a la madre de la infanticida Marcelina de haber asesinado a varios de sus hijos], a la ausencia absoluta del sentido de la maternidad, característica de la mujer congénitamente criminal, reflejada en el número y forma de los infanticidios cometidos (Del Campo, 1899: 278).

El saber clínico también utilizó el concepto de "locura puerperal" como discurso de justificación del ejercicio de poder punitivo. Es habitual en la producción académica y en la prensa, la asociación de las mujeres con enfermedades de orden psicológico/psiquiátrico, y la patologización de la biología femenina, vinculada siempre al desorden hormonal y mental. La tesis de Fernando Raffo (1888) escrita para optar al grado de Doctor en Medicina y Cirugía por la Universidad de Buenos Aires, fue la primera sobre el tema realizada en la Argentina. Su trabajo ayuda a comprender las concepciones de la época ligadas al imperativo de la maternidad, y la locura asociada a la dismaternidad y la criminalidad.

...la escuela Somática, oponiendo argumentos positivos a teorías banales y erróneas, busca en las lesiones anatómicas de las vísceras el punto de origen de trastornos simpáticos, que repercutiendo sobre las facultades intelectuales, esclarecen las naturaleza y patogenia de las alteraciones de la inteligencia. Entre las locuras denominadas simpáticas, el tipo más perfecto y de mayor interés para su estudio, es la que se relaciona con los trastornos y modificaciones de los órganos de la generación; a esta clase pertenece la locura puerperal (Raffo, 1888). 
El tipo penal de infanticidio ${ }^{5}$ fue derogado en 1994 por la ley 24.410 , sin embargo, persiste en el sentido común de la práctica jurídica y opera para criminalizar la desviación del mandato materno. Así, mujeres que han vivido emergencias obstétricas como abortos espontáneos o cualquier otra circunstancia fuera de los cánones reconocidos como esperables, resultan blanco de la sanción normalizadora del castigo penal, visible, moralizante y ejemplificador. Tanto para el infanticidio como para el aborto el estereotipo que recae sobre la mujer es el mismo: "mala madre". Belén fue condenada por el "homicidio" de "su hijo" mediando "circunstancia extraordinaria de atenuación" con varias referencias del "desorden mental" que le había producido el "estado puerperal":

BELÉN actuó influida por ese "estado puerperal"; es decir, que el hecho analizado lo cometió en ese contexto de puerperio. $Y$ cabe adelantar que, como lo dije, ante la derogación de la figura atenuada del "infanticidio" y la consecuente imposibilidad de considerar el encuadramiento de este hecho en dicha figura atenuada, considero que debe tomarse a ese "estado puerperal" que afectó a la imputada como una "circunstancia extraordinaria de atenuación", prevista en el último párrafo del artículo 80 del Código Penal (Cámara penal. Sala III. Tucumán, Belén s/homicidio doblemente agravado por el vínculo y alevosía 19/04/2016).

Lo importante en este caso es entender que lo que vivió Belén fue un aborto espontáneo. ¿Cómo es que una conducta que no es un delito pasa a ser un crimen por el que una persona puede ser condenada a prisión perpetua? Lo que se castiga es el mandato no cumplido, la posibilidad de no maternar, la desviación de la función reproductora a la que el discurso médico -o criminología clínica- llamó indistintamente "brujería", "locura", "dismaternidad". La locura-femenina, ligada a la patologización de la biología-femenina, fue asociada principalmente al estado puerperal como factor desencadenante de la criminalidad-femenina. "La mujer criminal, se decía, podía presentar un particular estado pasional que trastornara su estado psicológico y destruyera su sentido moral." (Di Corleto, 2018: 224)

La penalización del aborto medicaliza el cuerpo de las mujeres, las maternaliza, regula su sexualidad, condiciona su vida a las consecuencias punibles de la forma en que eligen vivirla, y vuelve estigma la posibilidad de gestar -marca de la diferencia sexual respecto al hombre- porque la convierte en un mandato, una experiencia a la que están obligadas solo por "ser mujer". A lo largo de la historia, los estereotipos de criminalización de la sexualidad femenina continúan vigentes. Belén no fue masacrada ni quemada en la hoguera, pero sí sometida a un proceso de violencia institucional con claras reminiscencias a la misoginia de la inquisición y el positivismo.

\footnotetext{
${ }^{5}$ Art. 81.2 (derogado):"Se impondrá reclusión hasta tres años o prisión de seis meses a dos años a la madre que, para ocultar su deshonra, matare a su hijo durante el nacimiento o mientras se encontrara bajo la influencia del estado puerperal..."
} 


\section{Decidir sobre nuestras vidas}

El caso Belén nos muestra la impronta del androcentrismo en la dominación patriarcal del cuerpo, traducido en prácticas de violencia institucional que limitan el derecho al aborto seguro, y la vigencia de la estructura inquisitorial en el uso del discurso jurídico/médico para construir una casuística del delito reproductora de la lógica producción/reproducción capitalista asociando a la mujer al imperativo de la maternidad.

En este trabajo analizamos la incidencia del poder punitivo en el cuerpo de las mujeres, castigando e imponiendo patrones de acción, e incluimos el género como categoría disruptiva que, si bien define roles sociales vinculados al sexo masculino y femenino, puede operar como terreno de resistencia en su versión performativa, cuestionando y modificando significados de masculinidad y feminidad en función de la soberanía de los cuerpos. El derrotero médico y jurídico que Belén debió enfrentar refleja un uso y aplicación de normas de acuerdo a asunciones y estereotipos arcaicamente machistas, y una construcción del "género femenino" en correspondencia con la imagen patriarcal que los hombres tienen de las mujeres.

Belén no fue quemada en la hoguera, tampoco deseó la maternidad, pero gestó y tuvo un aborto espontáneo, lo que derivó en un largo proceso de violencia institucional desde su ingreso al Hospital con dolor abdominal hasta 29 meses presa acusada de matar a su "hijo".

La crítica feminista advierte y cuestiona las normas y mecanismos de violencia institucional que en la práctica configuran un modelo de prohibición total, echando luz sobre el trasfondo moral de la penalización del aborto que lejos de promover la protección de la vida intrauterina o evitar muertes maternas, refuerza los estereotipos de género que imponen a todas las mujeres la maternidad como función natural y vulneran el derecho a la igualdad y la libertad.

El olvido respecto de los intereses de las mujeres embarazadas plasmado tanto en los discursos por la penalización del aborto, que sostienen la criminalización de la "mujer-mala-madre" que rehúsa a seguir su "función materna", como en los que se inclinan por la despenalización y buscan políticas tolerantes de control de daños que garanticen el desempeño del rol en condiciones seguras, es fiel reflejo del biopoder de medicalización y maternalización al que son sometidos los cuerpos gestantes, y de la nula recepción de las vivencias de quienes no desean la imposición del injusto y ficticio "mandato materno".

Lejos de un análisis exhaustivo y acabado, el conjunto de consideraciones en este trabajo abordadas, pretende ser un esbozo introductorio para estudios posteriores, en la línea de aproximarnos desde los aportes de los feminismos, al cuestionamiento a los patrones patriarcales vigentes en el sistema de justicia, y a posibles líneas de acción que demanda urgente la complejidad del acceso al aborto seguro en Argentina. 


\section{Referencias bibliográficas}

ANTONY, Carmen. "Criminología, victimología y movimiento feminista. Estado actual y perspectivas de integración en la criminología del siglo XXI", en Hacia una criminología feminista. Violencia, androcentrismo, justicia y derechos humanos. Bas. As.: UNDAV Ediciones, 2017.

ARRUZZA; Bhattacharya, Tithi; Fraser, Nancy. Feminismo para el 99\% Un manifiesto.Bs. As.:Rara Avis, 2019.

BARRANCOS, Dora. "Aborto legal como derecho humano fundamental", en Pecheny, Mario; Herrera, Marisa (comp.) (2019) Legalización del aborto en la Argentina. Bs. As.: Ediciones UNGS, 2019.

BODELÓN, Encarna. "Violencia institucional y violencia de género", en Anales de la Cátedra Francisco Suárez, 48 (2014), 131-155, Barcelona, 2014.

BUTLER, Judith. "Sujetos de sexo/género/deseo", en El género en disputa. Bs. As.: Paidós, 1990;2018.

DEL CAMPO, Ricardo "Madres criminales. Los infanticidios de La Magdalena", Criminalogía Moderna, Año II, 1899, N9

DI CORLETO, Julieta. Malas madres. Aborto e infanticidio en perspectiva histórica. Bs. As.: Didot, 2018.

FEDERICI, Silvia. Calibán y la bruja. Mujeres, cuerpo y acumulación originaria. Bs. As.: Tinta Limón, 2015.

INGENIEROS, José. Criminología, en Ingenieros, José (1962). Obras completas. Buenos Aires: Mar Océano, 1916.

KRAMER, Heinrich y Sprenger, Jacob. Malleus maleficarum. El martillo de las brujas. Traducción de Miguel Jiménez Monteserán. Valladolid. España, $1486 ; 2004$.

LARRAURI, Elena. "Una crítica feminista al derecho penal”, en Mujeres y sistema penal. Violencia doméstica. Barcelona: BdeF, 2008.

LOMBROSO, Cesare "La dismaternidad en la mujer delincuente", Criminalogía Moderna, Año II, 1899, N7

LOMBROSO, Cesare y Ferrero, Guglielmo. "Criminal Woman, the Prostitute, and The Normal Woman". Durham/London: Duke University Press, 1893;2004.

PRECIADO, Paul B. "Procreación políticamente asistida y heterosexualismo de Estado" y "Huelga de úteros", en Un apartamento en Urano. Crónicas del cruce. Barcelona: Anagrama, 2019.

RAFFO, Fernando. "Locura puerperal". Tesis para optar al grado de Doctor en Medicina y Cirugía por la Universidad de Buenos Aires, 1888, en Revista Temas de historia de la psiquiatría argentina, Volumen XV, 2012, N³2

RAMÓN Michel, Agustina. "El fenómeno de inaccesibilidad del aborto no punible", en Bergallo, Paola (2011) (comp.) Aborto y justicia reproductiva. Bs. As.: Editores del Puerto, 2011.

SCOTT, Joan. "El género: una categoría útil para el análisis histórico", en Marta Lamas (comp.) El género: la construcción cultural de la diferencia sexual. México: Programa Universitario de Estudios de Género. UNAM, 1996.

SEGATO, Rita. Las estructuras elementales de la violencia. Ensayos sobre género entre la antropología, el psicoanálisis y los derechos humanos. Bs. As.: Prometeo, 2010.

WITTIG, Monique. La Pensée straight. Paris: Balland, 2001.

ZAFFARONI, Eugenio Raul. "Segunda conferencia", en La palabra de los muertos. Conferencias de criminología cautelar. Bs. As.: Ediar, 2011.

"El crimen de la Magdalena: Un Monstruo de Ferocidad, Cinco Niños muertos por su Madre", La prensa, 26 de julio, 1899. 